\title{
Assessment of arch width changes in Class I and Class II Division 1 patients treated with fixed orthodontics
}

\author{
Umesh Parajuli* (D) , Manish Bajracharya² (D), Manju Pandey', \\ Ima Gurung ${ }^{3}$, Sapna Laxmi Tuladhar ${ }^{4}$ iD
}

'Department of Orthodontics, College of Dental Surgery, Gandaki Medical College, ${ }^{2}$ Department of Orthodontics, National Academy of Medical Sciences, Bir hospital, ${ }^{3}$ Perfect Dental Care Center, Pokhara, ${ }^{4}$ Department of Prosthodontics, College of Dental Surgery, Gandaki Medical College

\begin{abstract}
Background: The orthodontic treatment should aim to maintain the inter-canine and inter-molar width to that of the pre-treatment values. The study was conducted with objective to evaluate arch width changes in Class I and Class II Div 1 patients treated with fixed orthodontics. Methods: This was a hospital-based cross-sectional study with two study groups. The first group included patients with Class I malocclusion, treated with four first premolar extractions and the second group included patients with Class II Div 1 malocclusion, treated with upper two first premolar extractions. The inter-canine and inter-molar width of the pre and post-treatment study model were measured. To compare the changes observed amongst two groups, independent samples t-test was performed. A paired sample t-test was used to evaluate the treatment changes within each group. Results: There was significant increase in inter-canine width in both maxillary and mandibular arches in both the groups. In Class I extraction group there was significant decrease in the inter-molar width in both maxillary and mandibular arches. The Class II Div1 maxillary extraction group also showed significant increase in inter-canine width in both maxillary and mandibular arches. In the same group there was decrease in posttreatment inter-molar width in both arches with significant decrease in the maxillary inter-molar width. Conclusion: There was increase in inter-canine width in both Class I extraction group and Class II Div 1 maxillary extraction group with decrease in inter-molar width in both the groups.
\end{abstract}

Keywords: Inter-molar width, inter-canine width, pre-treatment, post-treatment

\section{*Correspondence:}

Dr. Umesh Parajuli, MDS

Associate Professor, Department of Orthodontics, College of Dental Surgery, Gandaki Medical College

Email: drumeshparajuli@gmail.com

Submitted: May 10, 2021

Accepted: June 10, 2021

To cite: Parajuli U, Bajracharya M, Pandey M, Tuladhar SL. Assessment of arch width changes in Class I and Class II Division 1 patients treated with fixed orthodontics. JGMC Nepal. 2021;14(1):3-7.

DOI: 10.3126/jgmcn.v14i1.37023

Mobile no: +977-9856022297

\section{INTRODUCTION}

It has been documented that if there is increase in dental arch width during orthodontic treatment and it tends to relapse to pre-treatment values after retention. ${ }^{1-4}$ The orthodontic treatment should aim to maintain the inter-canine and inter-molar width to that of pre-treatment values which will give better stability. The pre-treatment inter-canine and inter-molar width values represent better position for balance of surrounding muscles. ${ }^{5}$

The stability of post orthodontic treatment depends on many factors. Amongst these factors the maintenance of pre-treatment inter-canine and inter-molar width has been broadly discussed by many researchers and has been documented to be detrimental in stability. ${ }^{6}$ Post- treatment arch width depends on multitude of factors like the amount of crowding, arch length tooth size discrepancy, displacement, inclination and rotation of canines and molars. ${ }^{7}$ The variation in archwire dimensions used for treatment is also one of the factors 
which should be considered for alteration in post-treatment arch width. ${ }^{7,8}$ The fixed orthodontic treatment in our set up is done with the commercially available stock archwires.

This study aims to determine the maxillary and mandibular pre and post treatment inter-canine and inter-molar arch width in Class I and Class II Div 1 malocclusion groups treated with four first premolar extractions and upper two first premolar extractions respectively. This study also aims to compare the arch width dimensions between the two groups both pre and post-treatment.

\section{METHODS}

This was a hospital-based cross-sectional study conducted at College of Dental Surgery, Gandaki Medical College for a period of 10 months from April 2020 to January 2021 after obtaining ethical clearance from institutional review board (Ref no: 021/2076/2077). Sample size calculation was based on $80 \%$ power and significance level of $5 \%{ }^{9}$ and considering 1.5 as maximum tolerable error rate and based on standard deviation of $2.5 . \mathrm{N}=[\mathrm{Z}+(1-\beta)]^{2} \mathrm{X} \mathrm{SD} /$ $\mathrm{L}^{2}=(1.96+0.84)^{2} \mathrm{X} 2.5^{2} \quad / 1.5 \mathrm{X} 1.5=19.21$. Where, $\mathrm{Z}=$ Confidence interval $(95 \%, \mathrm{CI}=1.96), \beta=$ probability of type II error $=0.16$, Standard Deviation $=2.5, \mathrm{~L}=$ tolerable error= $1.5, \mathrm{~N}=$ Sample size. The sample came to be 20 in each group. The number of sample size included was 60 with 30 samples in each group. The inclusion criteria were 1) Patients with Angles Class I malocclusion treated with four first premolar extractions 2) Angles Class II malocclusion with upper two first premolar extractions 3) Treated with fixed orthodontic treatment with MBT 0.022" Slot. Exclusion criteria were 1) Patients with congenitally missing teeth or malformed teeth 2) Any extractions done due to caries or any other pathology 3) Those patients who had undergone expansion of arches with expansion appliances. The samples were screened on the basis of stratified sampling from the pre and post-treatment orthodontic records that has completed orthodontic treatment and from those with ongoing treatment; the records were obtained after completion of the treatment. The first group consisted of patients with Class I malocclusion, treated with four first premolar extractions and the second group consisted of patients with Class II Div 1 malocclusion, treated with upper two first premolar extractions.

Pre-treatment (T1) and post-treatment (T2) study casts of the cases were obtained. The cases were treated with MBT 0.022" slot prescription with commercially available archwires, natural arch-form of single company by a sin- gle orthodontist. The cases were treated between January 2015 to December 2020.Most of the cases were of moderate anchorage and were treated with two stage retraction. The canines were retracted with sliding mechanic and the four incisors were retracted with loop mechanics. The archwire sequence of the treatment was 0.014 " NiTi, 0.018"NiTi, 0.016 x 0.022"NiTi, 0.017 X 0.025"SS, 0.019 $\mathrm{X} 0.025 " \mathrm{NiTi}$ and $0.019 \mathrm{X} 0.025$ "SS. This study compared the pre and post-treatment arch form in two study groups. The inter-canine and inter-molar width of the pre and post-treatment study model were measured with digital vernier caliper with accuracy of $0.01 \mathrm{~mm}$ (Aero space company, India) by an orthodontist . The landmarks used for measurements were 1) maxillary inter-canine width between the height of contour points on the main buccal ridge located at the cervical third of the canines, 2) maxillary inter-molar width between the height of contour points located gingival to buccal grooves of the first molars, 3) mandibular inter-molar width between the height of contour points located gingival to main buccal pits of the first molars and 4) mandibular inter-canine width between the height of contour points on the buccal ridge located at the cervical third of the canines.Thirty three percentages of the samples that is 20 study models were re-measured by same investigator after two weeks and intra-class coefficient correlationwas used to see for intra-examiner reliability. The data management was performed using SPSS software (version 20; SPSS Inc., Chicago, IL, USA). Means and standard deviations of inter-canine and inter-molar width were calculated. To compare the changes observed amongst two groups, independent samples t-test was performed. A paired sample t-test was used to evaluate the treatment changes within each group. The results were considered significant at the $5 \%$ uncertainty level $(\mathrm{P}<0.05)$.

\section{RESULTS}

Amongst the 60 samples, 30 samples were in Class I group and 30 samples were in Class II Div 1 group. The average age in Class I group was $15.63 \pm 2.67$ years with $12(40 \%)$ male and $18(60 \%)$ female. The average age in Class II Div 1 was $17.70 \pm 4.28$ years with $14(46.67 \%)$ male and $16(53.33 \%)$ female. Intra-examiner reliability with intra-class coefficient ranged from 0.94 to 0.99 suggesting reliability in intra-examiner measurements. The inter-canine and inter-molar width in both maxillary and mandibular arch were slightly greater in Class I group as compared to Class II group but there was no statistically significant difference (Table 1). There was significant increase in inter-canine width in both maxillary and mandibular arches 
when the pre-treatment Class I extraction group was compared with post-treatment (Table 2). In the same group there was significant decrease in the inter-molar width in both maxillary and mandibular arches (Table 2). The Class II Div1 maxillary extraction group also showed increase in inter-canine width in both maxillary and mandibular arches which was significant $(\mathrm{P}<0.001$; Table3). In the same group there was decrease in post-treatment inter-molar width in both arches with significant decrease in the maxillary inter-molar width $(\mathrm{P}<0.001$; Table 3 ). The post-treatment values in Class I and Class II Div 1 groups showed comparable maxillary inter-canine width. The Class I post-treatment maxillary inter-molar width $(53.97 \pm 2.03 \mathrm{~mm})$ although decreased with treatment was greater as compared to the Class II Div 1 post-treatment inter-molar width $(52.15 \pm 2.19 \mathrm{~mm})(\mathrm{P}=0.001$; Table 4). The Class I post-treatment group had significant greater mandibular inter-canine width $(31.07 \pm 1.76 \mathrm{~mm})$ as compared to Class II Div 1 post-treatment group $(28.97 \pm 2.28$ $\mathrm{mm}$; Table 4). In contrary the Class I post-treatment group had significantly smaller mandibular inter-molar width as compared to the Class II Div1 post-treatment group (P value $<0.001$; Table 4).

Table 1: Comparison of pre-treatment maxillary and mandibular inter-canine and inter-molar arch width $(\mathrm{mm})$ with independent sample t-test

\begin{tabular}{lccc}
\hline \multicolumn{1}{c}{ Arch width } & $\begin{array}{c}\text { Class I Mean } \pm \\
\text { SD(n=30) }\end{array}$ & $\begin{array}{c}\text { Class II Mean } \pm \\
\mathbf{S D}(\mathbf{n}=\mathbf{3 0})\end{array}$ & P Value \\
Maxillary inter-canine & $36.10 \pm 2.45$ & $35.47 \pm 1.57$ & 0.241 \\
Maxillary inter-molar & $55.99 \pm 2.93$ & $54.49 \pm 3.02$ & 0.056 \\
Mandibular inter-canine & $28.99 \pm 2.46$ & $28.49 \pm 2.28$ & 0.408 \\
Mandibular inter-molar & $52.33 \pm 2.89$ & $52.16 \pm 2.29$ & 0.807 \\
\hline
\end{tabular}

*Statistically significant at $\mathrm{P}<0.05$

Table2: Comparison of pre-treatment and post-treatment maxillary and mandibular arch width ( $\mathrm{mm}$ ) in Class I extraction group with paired sample t- test

\begin{tabular}{lccr}
\hline \multicolumn{1}{c}{ Arch width } & $\begin{array}{c}\text { Pre-treatment } \\
\text { (T1) } \\
\text { Mean } \pm \text { SD }\end{array}$ & $\begin{array}{c}\text { Post- treatment } \\
\text { (T2) } \\
\text { Mean } \pm \text { SD }\end{array}$ & P Value \\
Maxillary inter-canine & $36.10 \pm 2.45$ & $39.12 \pm 1.84$ & $<0.001^{*}$ \\
Maxillary inter-molar & $55.99 \pm 2.93$ & $53.97 \pm 2.03$ & $<0.001^{*}$ \\
Mandibular inter-canine & $28.99 \pm 2.46$ & $31.07 \pm 1.76$ & $<0.001^{*}$ \\
Mandibular inter-molar & $52.33 \pm 2.89$ & $49.76 \pm 1.68$ & $<0.001^{*}$ \\
\hline
\end{tabular}

*Statistically significant at $\mathrm{P}<0.05$
Table3: Comparison of pre-treatment and post-treatment maxillary and mandibular arch width ( $\mathrm{mm}$ ) in Class II Div 1 maxillary extraction group with paired sample t-test

\begin{tabular}{lcll}
\hline \multicolumn{1}{c}{ Arch width } & $\begin{array}{c}\text { Pre-treatment } \\
\text { (T1) Mean } \pm \text { SD }\end{array}$ & $\begin{array}{l}\text { Post- treatment } \\
\text { (T2) Mean } \pm \text { SD }\end{array}$ & P Value \\
Maxillary inter-canine & $35.47 \pm 1.57$ & $38.27 \pm 1.79$ & $<0.001^{*}$ \\
Maxillary inter-molar & $54.49 \pm 3.02$ & $52.15 \pm 2.19$ & $<0.001^{*}$ \\
Mandibular inter-canine & $28.49 \pm 2.28$ & $28.97 \pm 2.28$ & 0.196 \\
Mandibular inter-molar & $52.16 \pm 2.29$ & $51.92 \pm 1.79$ & 0.293 \\
\hline
\end{tabular}

*Statistically significant at $\mathrm{P}<0.05$

Table 4: Comparison of post-treatment maxillary and mandibular inter-canine and inter-molar arch width (mm) in Class I extraction group and Class II Div 1 maxillary extraction group with independent sample t-test.

\begin{tabular}{lccc}
\hline \multicolumn{1}{c}{ Arch width } & $\begin{array}{c}\text { Class I } \\
\text { Mean } \pm \text { SD }\end{array}$ & $\begin{array}{c}\text { Class II } \\
\text { Mean } \pm \text { SD }\end{array}$ & P Value \\
Maxillary inter-canine & $39.12 \pm 1.84$ & $38.27 \pm 1.79$ & 0.073 \\
Maxillary inter-molar & $53.97 \pm 2.03$ & $52.15 \pm 2.19$ & $0.01^{*}$ \\
Mandibular inter-canine & $31.07 \pm 1.76$ & $28.97 \pm 2.28$ & $<0.001^{*}$ \\
Mandibular inter-molar & $49.76 \pm 1.68$ & $51.92 \pm 1.79$ & $<0.001^{*}$ \\
\hline
\end{tabular}

*Statistically significant at $\mathrm{P}<0.05$

\section{DISCUSSION}

In the present study the inter-canine and inter-molar widths in both maxillary and mandibular arches were less in Class II Div 1 groups as compared to Class I group although there were no significant differences (Table 1). This was similar to the study done by $\mathrm{Oz}$ et $\mathrm{al}^{1}$ in Turkish population. This could be attributed to the mesial drift of the maxillary molars.

Our study showed significant increase in the maxillary and mandibular inter-canine width in Class I extraction group (Table 2). This is in unison with the study done by Aksu et $\mathrm{al}^{7}$. In our study there was significant decrease in the inter-molar width in both the arches while Aksu et al. ${ }^{7}$ in their study found decrease only in the mandibular arch. Makhbulet al. ${ }^{2}$ found similar findings in their study where they studied the arch width dimension changes in mandibular arch in extraction and non extraction group. This is also correlated to the normal growth changes as seen in a 20-year longitudinal study done by Ward et al. ${ }^{10}$ in which the untreated group showed increase in all arch width dimensions except the lower molars which showed small decrease. In contrary to our study $\mathrm{Oz}$ et al. ${ }^{1}$ and Gianelly ${ }^{11}$ reported no decrease in arch width with either extraction or non-extraction mechanics.

In our second group, Class II Div 1 with extraction of max- 
illary first premolar in both quadrants we wanted to see whether there were any changes in the arch width dimension with no extraction in the mandibular arch. This group had significant increase in maxillary inter-canine width and significant decrease in the maxillary inter-molar width which is similar to the Class I extraction group (Table $2 \&$ $3)$. In contrary there were no significant changes in the mandibular inter-canine and inter-molar arch width in the Class II Div 1 with extraction only in maxillary arch. Shirazi et al. ${ }^{9}$ in his study found that in Class II Div 1 extraction group there was significant increase in mandibular inter-molar arch width which contradicted with findings in our study which showed marginal decrease in mandibular width although statistically not significant (Table 3). This could be attributed to the case selection, skeletal pattern of malocclusion, the form of archwires used by the clinician and degree of adjustments made on the stainless steel archwires considering the pre-treatment arch form.

The pre-treatment arch width dimensions of the two groups were comparable so post-treatment comparison was also done between the two groups (Table $1 \& 4$ ). The post-treatment mandibular inter-molar width in Class II Div 1 group was greater than the Class I group which is different as seen with the pre-treatment comparison which showed the Class II Div 1 group had smaller inter-molar width as compared to the Class I group. This could be attributed to the non-extraction in the mandibular arch in Class II Div 1 group.

Considering the changes in the archwidth dimensions seen clinicians should consider pre-treatment arch form while selecting the archwires. The individualized customized archwires would be the best option but considering the high cost of the treatment clinicians can adjust the stainless steel archwires according to the pre-treatment arch form. This could reduce the changes in archwidth dimensions which will help maintain the stability. To reduce the bias similar study can be extended to multiple centers with multiple treating clinicians with different malocclusion groups, different archwire forms but with similar standard protocol. The arch width dimensions can be further studied in different ethnic groups of Nepal and the arch form recommendations can be made for particular ethnic group which might reduce the probability of changes in post treatment arch width dimensions.

\section{CONCLUSION}

This study showed that there was increase in inter-canine width in both Class I extraction group and Class II Div 1 maxillary extraction group. There was decrease in inter-molar width in both the groups.

\section{SOURCE OF FINANCIAL SUPPORT: None}

ACKNOWLEDGEMENT: The authors would like to express gratitude of thanks to the College of Dental Surgery-Gandaki medical college and department of Orthodontic for support to conduct the research.

CONFLICTS OF INTEREST: No potential conflict of interest relevant to this article was reported.

\section{REFERENCES}

1. Oz A A, Oz A Z, Yaziciooğlu S, Arici N, Ozer M, Arici S. Comparison of arch width changes following orthodontic treatment with and without extraction using three-dimensional models. Niger J Clin Pract. 2017;20(5):581-6. DOI: 10.4103/11193077.181389

2. Makhbul MZM, Hassan WNW. Lower dental arch widths changes following fixed dental orthodontic treatment. Annals of Dentistry University of Malaya. 2018;25(1):17-22.

3. Johnson KC. Cases six years postretention. Angle Orthod. 1977;47:210-21. DOI: 10.1043/0003-3219(1977)047<0210:csyp>2.0.co;2 PMID: 268952.

4. Little RM, Wallen TR, Riedel RA. Stability and relapse of mandibular anterior alignment-first premolar extraction cases treated by edgewise orthodontics. Am J Orthod. 1981;80:349-65. DOI: 10.1016/0002-9416(81)90171-8 PMID: 6945805.

5. RiedelRA.Review of theretention problem.AngleOrthod.1960; 6:179-99. DOI: 10.1043/0003-3219(1960)030<0179:AROTRP>2.0.CO;2 PMID: 13741513.

6. Rosseto MC, Palma FM, Ferreira RI, Pinzan A, Vellini-Ferreira F. Comparative study of dental arch width in plaster models, photocopies and digitized images. Braz Oral Res. 2009;23:190-5. DOI: 10.1590/s1806-83242009000200016 PMID: 19684955.

7. Aksu M, Kocadereli I.Arch widthchanges in extraction and nonextraction treatment in class I patients. Angle Orthod. 2005; 75:948-52. DOI: 10.1043/0003-3219(2005)75[948:AWCIEA]2.0.CO;2

8. Germec-Cakan D, Taner TU, Akan S. Arch-width and perimeter changes in patients with borderline Class I malocclusion treated with extractions or without extractions with air-rotor stripping. Am J Orthod Dentofacial Orthop. 2010;137:734. e1-7. DOI: 10.1016/j.ajodo.2009.12.023 PMID: 20685525. 
9. Shirazi S, Kachoei M, Shahvaghar-Asl N, Shirazi S, Sharghi R. Arch width changes in patients with Class II division 1 malocclusion treated with maxillary first premolar extraction and non-extraction method. J Clin Exp Dent. 2016;8(4):e403-8.

10. Ward DE, Workman J, Brown R, Richmond S. Changes in arch width: A 20-year Longitudinal Study of Ortho- dontic Treatment. Angle Orthod. 2006;76:6-13. DOI: 10.1043/0003-3219(2006)076[0006:CIAW]2.0.CO;2

11. Gianelly AA. Arch width after extraction and nonextraction treatment. Am J Orthod Dentofacial Orthop. 2003;123:25-8. DOI: 10.1067/mod.2003.57_PMID: 12532059. 